\title{
EVALUATION OF PSYCHOLOGICAL DISTRESS IN CANCER PATIENTS
}

\author{
RASHMI ANUPOZU, RAMA BOBBA, MANIDHAR VANAMALA
}

Department of Pharm-D, Malla Reddy Institute of Pharmaceutical Sciences, Affiliated to Jawaharlal Nehru Technological University Hyderabad, Maisammaguda, Hyderabad, Telangana, India. Email: anupozurashmi095@gmail.com

Received: 16 June 2020, Revised and Accepted: 10 July 2020

ABSTRACT

Objective: The main objective of the present study is to determine the depression and anxiety using standardized rating scales in cancer patients.

Methods: This prospective observational study was performed in 120 cancer patients at a local government cancer hospital. Subjects were interviewed and data were collected using standard Patient Health Questionnaire-9 (PHQ-9) and Generalized Anxiety Disorder-7 (GAD-7) questionnaires. The obtained data were analyzed using SPSS software version 26.

Results: Out of 120 patients, $75.8 \%$ were male and $24.2 \%$ were female. The maximum number of subjects (n=66, 55\%) were within the age group of 41-60 years and from the urban region (54.2\%). Analyzing the depression status from the PHQ-9 questionnaire, severe depression was seen high among females (31\%) when compared to males (19.8\%). From the scores obtained by the GAD-7 questionnaire, it was found that males with normal anxiety $(26.4 \%)$ and severe anxiety $(11 \%)$ were more when compared to females. On performing regression, females were 0.572 times at a higher risk of developing depression and 2.005 times likely to have GAD when compared to males.

Conclusion: The present study suggests that majority of subjects with psychiatric disorders are in the age group of 41-60 years and are from the urban region. Early screening of the cancer patients for depression and GAD using validated questionnaires such as PHQ-9 and GAD-7 and providing appropriate counseling or therapy on a timely basis helps them to manage their adverse symptoms and boosts the mental health of the subjects.

Keywords: Psychological distress, Patient Health Questionnaire-9, Generalized Anxiety Disorder-7, Cancer, Mental health, Anxiety.

(C) 2020 The Authors. Published by Innovare Academic Sciences Pvt Ltd. This is an open access article under the CC BY license (http://creativecommons. org/licenses/by/4. 0/) DOI: http://dx.doi.org/10.22159/ajpcr.2020.v13i10.38705

\section{INTRODUCTION}

Sorrow and grief are normal reactions to some painful life events a person experiences, which is associated with threatened or actual loss. These are also seen in other cases where a person is diagnosed with a life-threatening condition like cancer [1]. Psychiatric oncology is the study of psychological response in all the stages of cancer by the patients and the behavioral and social factors that may impact the disease process. More than one-third of cancer patients experience anxiety and depression [2]. There is evidence that psychological distress, especially depression, contributes to the poor prognosis in cancer patients [3]. Neuroendocrine activation due to stress had very little effect on the growth of the primary tumor but generates a 30 -fold increase in the distant tissue metastasis and these effects are thought to be mediated by beta-adrenergic signaling [4]. In animal models of disease, behavioral stress is known to promote the tumor angiogenesis and thereafter promote the malignant cell growth [5]. Research also suggests that a link between stressful events and cancer be the immune system. On an average, 7 million deaths due to cancer worldwide are being recorded per year [6] and this number is predicted to be increased to 12 million by 2020 and is most commonly diagnosed in elderly population [7].

Underdiagnosed and untreated psychiatric morbidity in cancer patients may influence morbidity, more frequent hospitalizations, leading to a greater burden. Poor adherence to the therapy may finally lead to poor quality of life and increased mortality [8]. Thus, early detection through appropriate screening tests and treatment, ranging from support groups and counseling through psychotherapy, is of utmost importance in cancer care [9] and many studies also support the advantage of these screening tests [10]. But unfortunately, this is missing in most palliative care settings in developing countries like India.

In light of these studies, the rationale for conducting the present study is to screen cancer patients for the presence of depression and anxiety disorders using standardized rating scales.

\section{METHODOLOGY}

This is a prospective observational study conducted for a period of 6 months from October 2019-March 2020 at a government cancer hospital, Hyderabad. The study protocol was prepared, submitted, and approved by the hospital ethics committee (Regd No: ECR/227/Inst/ AP/2013/RR-16). The study was initiated after the ethics approval. Evaluation of psychological distress using the standard questionnaires (PHQ-9 and GAD-7) was conducted in 120 cancer in-patients.

\section{Study criteria}

The study is carried out using the following factors:

\section{Inclusion criteria}

The following criteria were included in the study:

- Patients diagnosed with cancer.

- Subjects with age limit of $\geq 21$ years.

- Subjects of either gender.

\section{Exclusion criteria}

The following criteria were excluded from the study:

- Pregnant women.

- Subjects with $\leq 20$ years.

- Pediatric patients.

- Patients with abnormal mental status.

- Patients not willing to give consent.

\section{MATERIALS}

\section{Patient Health Questionnaire-9 (PHQ-9)}

PHQ is a self-reported questionnaire used as a diagnostic tool for mental disorders. It consists of nine questions which scores range from " 0 " (not at all) to "3" (nearly every day) according to the DSN-IV criteria. A score of 5 states mild depression, 10 as moderate, 15 as moderately severe, and 20 as severe depression in PHQ-9. A score of 9 or $\geq 10$ had a 
specificity of $88 \%$ and a sensitivity of $88 \%$ for major depression. Thus, the PHQ-9 questionnaire is a reliable and valid measure of depression severity and is a useful tool for research and clinical aspects [11].

\section{General anxiety disorder-7 (GAD-7) questionnaire}

GAD-7 is a 7-question anxiety scale used to assess the severity of anxiety in the patients. It scores ranges from " 0 " (not at all) to " 3 " (nearly every day). The cutoff scores 5 states mild level of anxiety, 10 as moderate level of anxiety and 15 as severe level of anxiety in GAD-7. This scale has good reliability, construct, factorial, criterion, and procedural validity. A cutoff score of 8 had $82 \%$ of specificity and $89 \%$ of sensitivity. Thus, GAD-7 is a valid and efficient instrument to assess for GAD and its severity in research and clinical practice [12]

\section{Statistical analysis}

Data were analyzed using Statistical Package for the Social Sciences version 26. Mean, frequency, standard deviation, percentage, Chi-square test, Student's $t$-test, and multinomial regression were performed at statistical significance ${ }^{*} \mathrm{p}<0.05$ to describe the data and the association between the variables.

\section{RESULTS}

\section{Sociodemographic characteristics}

Out of 120 subjects, maximum number of subjects were male, that is, $\mathrm{n}=91(75.8 \%)$ followed by females $(\mathrm{n}=29,24.2 \%)$. The mean age of the patients was 48.8 years ( $S D=12.73)$. All these subjects are divided into three different groups such as 21-40 years, 41-60 years, and $>60$ years age group. Majority of the subjects were within the age group of $40-60$ years $(n=66,55 \%)$ followed by $20-40$ years $(n=36$, $30 \%)$ and $>60$ years $(n=18,15 \%)$. Large number of subjects were from urban region $(n=65,54.2 \%)$ when compared to the rural region $(n=55$, $45.8 \%$ ). Sociodemographic details of the subjects are shown in Table 1.

\section{Psychiatric morbidity in males and females}

Interpretation of the depression state was done based on the scores obtained by the patients after answering the PHQ-9 questionnaire. Majority of the males had moderate intensity depression $(n=32,35.2 \%)$ followed by mild intensity $(n=19,20.9 \%)$ and severe intensity in $18(19.8 \%)$ male subjects. In females, the maximum number of subjects had a severe intensity of depression $(n=9,31 \%)$ followed by subjects with a moderate intensity of depression.

The intensity of anxiety was calculated in the subjects based on the scores obtained by the patients answering the GAD-7 questionnaire. About $26.4 \%$ of males and $13.8 \%$ of females were found to be normal with no GAD. However, the maximum number of males had moderate intensity anxiety $(n=30,33 \%)$ followed by mild $(n=27,29.7 \%)$. In females, the trend in the intensities of anxiety is similar to males, that is, maximum in moderate $(n=15,55.2 \%)$ followed by mild intensity $(n=6$, $20.7 \%$ ). Depression and anxiety in both males and females were found to be statistically significant at $\mathrm{p}<0.05$ (Table 2).

Gender as a risk factor for the intensity of depression and anxiety Table 3 shows the odds ratio for predicting the intensity of depression and anxiety. Multinomial logistic regression was performed to obtain

Table 1: Sociodemographic details of the subjects $(n=120)$

\begin{tabular}{lcc}
\hline Variables & $\mathbf{n}$ & $\mathbf{\%}$ \\
\hline Gender & & \\
$\quad$ Male & 91 & 75.8 \\
$\quad$ Female & 29 & 24.2 \\
Age group & & \\
21-40 years & 36 & 30 \\
41-60 years & 66 & 55 \\
$\quad$ 60 years & 18 & 15 \\
Place of residence & & \\
$\quad$ Rural & 55 & 45.8 \\
$\quad$ Urban & 65 & 54.2 \\
\hline
\end{tabular}

the values. As assessed from PHQ it showed that females were 0.572 times more likely to have severe depression, 0.538 times to have moderate depression, and 1.315 times to have mild depression than males. Assessing from GAD, females are 0.47 times to have mild intensity anxiety, 0.798 times to have moderate anxiety, and 2.005 times to have severe GAD when compared to males.

\section{Score distributions of PHQ-9 and GAD-7}

Mean PHQ-9 scores were higher in females when compared to males (female $14.49 \pm 5.75$ vs. male $14.19 \pm 5.75$ ) and also the means tend to decrease with the increase in age. Subjects from urban region mean scores were slightly higher when compared to the subjects in the rural region (urban $14.21 \pm 5.74$ vs. $14.14 \pm 5.75$ ). However, these results were found to be statistically non-significant as shown in Table 4.

Mean GAD-7 scores were also calculated and the results show that the mean scores were higher in females compared to males $(8.73 \pm 4.72$ vs. $8.59 \pm 4.78$ ) and also these means tend to decrease with the increase in age, that is, high mean scores in subjects $21-40$ years age group. The mean GAD-7 scores were high in the urban population when compared to the rural subjects $(8.62 \pm 4.77$ vs. $8.53 \pm 4.76)$, but the results were found to be statistically non-significant as shown in Table 4.

\section{DISCUSSION}

In our study, more than half of the cancer subjects enrolled are having a psychiatric diagnosis. The majority of the subjects were found within the age group 41-60 years in both males and females and are majorly from the urban region which is consistent with other studies [13,14]. As 41-60 years is the peak age for both males and females in earning their livelihood and household assests, they are likely to face more stress related to both financial and household issues [15] when compared to the other age group population. On performing the odds ratio, it was found that females are 0.572 times at a higher risk of developing depression and 2.005 times at a higher risk of developing severe GAD when compared to the males. However, recent evidence suggests that one of the main factors, that is, ovarian hormonal fluctuation, especially decrease in the estrogen levels, may contribute to the increased prevalence of depression and anxiety in women [16]. On this, the additional stress when diagnosed with a life-threatening conditions such as cancer, pain, and the use of chemotherapeutic agents directly or indirectly may further impose pressure [17] and thus a large percent of the population in this age group are under the psychiatric diagnosis.

Table 2: Psychiatric morbidity in males and females $(n=120)$

\begin{tabular}{llll}
\hline Gender & PHQ-9 (\%) & GAD-7 (\%) & p-value \\
\hline Males & & & $<0.0001^{*}$ \\
$\quad$ Minimal & 1.10 & 26.40 & \\
Mild & 20.90 & 29.70 & \\
$\quad$ Moderate & 35.20 & 33.00 & \\
$\quad$ Severe & 19.80 & 11.00 & $0.009^{*}$ \\
Females & & & \\
$\quad$ Normal & 24.10 & 13.80 & \\
Mild & 3.40 & 20.70 & \\
$\quad$ Moderate & 20.70 & 55.20 & \\
Severe & 31 & 10.30 & \\
\hline
\end{tabular}

*Significant at $\mathrm{p}<0.05$. PHQ-9: Patient Health Questionnaire-9,

GAD-7: Generalized Anxiety Disorder-7

Table 3: Gender as a risk factor for the intensity of depression and anxiety $(n=120)$

\begin{tabular}{llllllll}
\hline & PHQ & & & & GAD & & \\
\cline { 2 - 4 } & Mild & Moderate & Severe & & Mild & Moderate & Severe \\
\hline Females & 1.315 & 0.538 & 0.572 & 0.47 & 0.798 & 2.005 \\
Males & $\mathrm{a}$ & $\mathrm{a}$ & $\mathrm{a}$ & $\mathrm{a}$ & $\mathrm{a}$ & $\mathrm{a}$ \\
\hline
\end{tabular}

${ }^{a}$ Reference category (males). PHQ: Patient Health Questionnaire,

GAD: Generalized Anxiety Disorder 
Table 4: Score distributions of PHQ-9 and GAD-7 (n=120)

\begin{tabular}{|c|c|c|c|c|}
\hline \multirow[t]{2}{*}{ Variables } & \multirow[b]{2}{*}{ Mean (SD) } & \multicolumn{2}{|l|}{ PHQ-9 } & \multirow{2}{*}{$\begin{array}{l}\text { GAD-7 } \\
\text { p-value }\end{array}$} \\
\hline & & p-value & Mean (SD) & \\
\hline \multicolumn{5}{|l|}{ Gender } \\
\hline Male & 14.19 (5.759) & 0.807 & $8.59(4.789)$ & 0.89 \\
\hline Female & $14.49(5.759)$ & & $8.73(4.728)$ & \\
\hline \multicolumn{5}{|l|}{ Age group } \\
\hline 21-40 years & $14.23(5.63)$ & 0.764 & $8.66(4.666)$ & 0.94 \\
\hline $41-60$ years & $14.19(5.75)$ & & $8.59(4.789)$ & \\
\hline$>60$ years & $13.73(5.77)$ & & $8.11(4.861)$ & \\
\hline \multicolumn{5}{|c|}{ Place of residence } \\
\hline Rural & $14.14(5.759)$ & 0.947 & $8.53(4.76)$ & 0.63 \\
\hline Urban & $14.21(5.741)$ & & $8.62(4.779)$ & \\
\hline
\end{tabular}

PHQ-9: Patient Health Questionnaire-9, GAD-7: Generalized Anxiety Disorder-7

The presence of psychiatric disorder reflects an adverse impact of the ill-health on the patients. This finding suggests that these patients need to be under the eye of the mental health-care professionals on a fulltime basis in the oncology units which helps the patients to improve the quality of life and to cope up with their mental stress similar to the study concluded by Rukminingsih et al. [18].

The strength of our study is that all the subjects were interviewed face to face and no data were obtained from their family members or any other guardians. The use of standard questionnaires such as PHQ-9 and GAD-7 also increases the confidence in the results. The limitations of our study are that no effort was made to identify the psychosocial factors such as pain, palliative therapy, and different clinical variables such as socioeconomic pressures, level of dysfunction due to the disease, and social isolation that may influence the incidence of psychiatric conditions.

\section{CONCLUSION}

The present study suggests that the majority of subjects with psychiatric disorders were within the age group of 41-60 years and are from urban regions. Early screening of the cancer patients for depression and GAD using validated questionnaires such as PHQ-9 and GAD-7 and providing appropriate counseling or therapy on a timely basis helps them to manage their adverse symptoms and boosts the mental health of the patients.

\section{ACKNOWLEDGMENT}

We thank MNJ Government Cancer Hospital authorities for providing complete support and guidance during the collection and interpretation of data.

\section{AUTHORS' CONTRIBUTIONS}

Rashmi Anupozu was involved in the collection of data from the patients, preparation, and editing of the manuscript. Dr. Rama Bobba was involved in the organizing and reviewing of the manuscript. Manidhar Vanamala was involved in the collection of the data from the patients.

\section{CONFLICTS OF INTEREST}

The authors declare no conflicts of interest.

\section{AUTHORS' FUNDING}

Nil.

\section{REFERENCES}

1. Bukberg J, Penman D, Holland JC. Depression in hospitalized cancer patients. Psychosom Med 1984;46:199-212

2. Shiel WC. Medical Definition of Psycho-oncology. Medicine Net; 2018. Available from: https://www.medicinenet.com/script/main/art. asp?articlekey $=33446$.

3. Satin JR, Linden W, Phillips MJ. Depression as a predictor of disease progression and mortality in cancer patients: A meta-analysis. Cancer 2009;115:5349-61.

4. Sloan EK, Priceman SJ, Cox BF, Yu S, Pimentel MA, Tangkanangnukul V, et al. The sympathetic nervous system induces a metastatic switch in primary breast cancer. Cancer Res 2010;70:7042-52

5. Thaker PH, Han LY, Kamat AA, Arevalo JM, Takahashi R, Lu C, et al. Chronic stress promotes tumor growth and angiogenesis in a mouse model of ovarian carcinoma. Nat Med 2006;12:939-44

6. Rukminingsih F, Andayani TM, Rahmawati F, Widayati K. Healthrelated quality of life in early breast cancer patients with hormone responsive. Int J Pharm Pharm Sci 2018;10:47-9.

7. Piero NM, Joan NM. Cancer: A molecular curse? Int J Curr Pharm Res 2015;7:1-3.

8. Pinquart M, Duberstein PR. Depression and cancer mortality: A metaanalysis. Psychol Med 2010;40:1797-810.

9. Williams S, Dale J. The effectiveness of treatment for depression/ depressive symptoms in adults with cancer: A systematic review. Br J Cancer 2006;94:372-90.

10. Rost K, Nutting P, Smith J, Werner J, Duan N. Improving depression outcomes in community primary care practice: A randomized trial of the quEST intervention. Quality enhancement by strategic teaming. J Gen Intern Med 2001;16:143-9.

11. Kroenke K, Spitzer RL, Williams JB. The PHQ-9: Validity of a brief depression severity measure. J Gen Intern Med 2001;16:606-13

12. Spitzer RL, Kroenke K, Williams JB, Löwe B. A brief measure for assessing generalized anxiety disorder: The GAD-7. Arch Intern Med 2006:166:1092-7.

13. Wolch JR. Public problems: The management of urban distress. Economic Geography. Vol. 64. United Kingdom: Taylor \& Francis, Ltd.; 1988. p. 286-8.

14. National Cancer Registration and Analysis Service (NCRAS). The Effect of Rurality on Cancer Incidence and Mortality. Available from: http://www.ncin.org.uk/publications/data_briefings/rurality.

15. Nauriyal DK, Negi NS, Gairola RK. Migration, Gender and Home Economics in Rural North India. United Kingdom: Taylor \& Francis, Ltd.; 2019

16. Gupta M, Dahiya J, Marwaha RK, Dureja H. Therapies in cancer treatment: An overview. Int J Pharm Pharm Sci 2015;7:1-9.

17. Albert PR. Why is depression more prevalent in women? J Psychiatry Neurosci 2015;40:219.

18. Chaturvedi SK. Psychiatric oncology: Cancer in mind. Indian J Psychiatry 2012;54:111. 